\title{
Pharmacodynamic effect of dipyridamole on thallium-201 myocardial perfusion in progressive systemic sclerosis with diffuse scleroderma
}

\author{
ANDRE KAHAN, JEAN Y DEVAUX, BERNARD AMOR, \\ CHARLES J MENKES, SIMON WEBER, JEAN M FOULT, \\ ALAIN VENOT, FRANÇOIS GUERIN, MICHEL DEGEORGES, AND \\ JEAN C ROUCAYROL
}

From the Departments of Rheumatology, Cardiology, and Nuclear Medicine, and the Institut de Rechercheso Thérapeutique et Pharmacologique Cliniques (IRT), René Descartes University, School of Medicine, Hôpitales Cochin, Paris, France

SUMmaRY We evaluated the effect of dipyridamole on thallium-201 myocardial perfusion in 23 을 patients with progressive systemic sclerosis (PSS) with diffuse scleroderma. Thallium-201 single $-\vec{f}$ photon emission computed tomography (SPECT) was performed at rest and after coronary $\mathbb{D}_{\mathbb{D}}$ artery vasodilatation with intravenous dipyridamole $(0 \cdot 14 \mathrm{mg} / \mathrm{kg} / \mathrm{min}$ for four minutes $)$. The left myocardium was divided into nine segments; each segment was graded as $2 \cdot 0,1 \cdot 5,1 \cdot 0,0 \cdot 5,03$

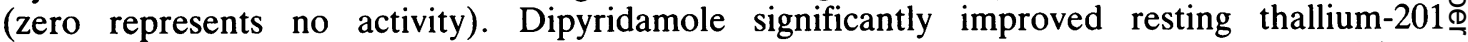
myocardial perfusion: the mean (SD) number of segments with thallium defects decreased frogn $\overrightarrow{0}$ $6 \cdot 0(2 \cdot 1)$ at rest to $4 \cdot 1(2 \cdot 5)$ after dipyridamole $(\mathrm{p}<0 \cdot 0001)$; the mean (SD) score in segments wi resting defects increased from $0.92(0.24)$ at rest to $1.13(0.38)$ after dipyridamole $\left(\mathrm{p}<0.0001 \overline{\text { a }} ;{ }^{\circ}\right.$ the mean (SD) global score per patient increased from $10 \cdot 2(1 \cdot 8)$ at rest to $11.4(2 \cdot 1)$ aftero dipyridamole $(\mathrm{p}<0.02)$; the global score increased by at least 2.0 in 12 patients and worsened by at least 2.0 in three patients only $(p=0.05)$. The results of this acute study suggest that some drugs with potent vasodilator activity on small coronary arteries may be beneficial in the treatment of $\mathbb{\Phi}^{\mathbb{Q}}$ PSS patients with thallium-201 myocardial perfusion abnormalities.

Primary scleroderma myocardial disease (PSMD) is an important complication of progressive systemic sclerosis (PSS) and accounts for a significant proportion of the mortality in this disease. ${ }^{1-4}$ The pathogenesis of primary scleroderma myocardial disease remains uncertain. ${ }^{1-3}$ The cause of the myocardial necrosis and fibrosis that occurs in the setting of normal extramural coronary arteries is not fully understood, and the possibility that these lesions are a reflection of a primary fibrous tissue overgrowth leading to secondary vascular compromise is still reasonable. ${ }^{1-3} 5-7$ Nevertheless, a growing body of evidence from studies of the heart and other organs involved in progressive systemic sclerosis suggests that the vascular system per se

Accepted for publication 24 March 1986.

Correspondence to Dr André Kahan, Department of Rheumatology, Hôpital Cochin, 27 rue du Faubourg Saint Jacques, 75674 Paris Cedex 14, France. may be the primary target organ in PSS and that the myocardial lesion is a manifestation of focal ischaemic injury resulting from functional vascular disease, with or without accompanying structural change. ${ }^{1-3}$ 8-14

Bulkley reported a high prevalence of myocardial contraction band necrosis-a histological lesion seen in the setting of ischaemic injury followed 5 by reperfusion-and speculated that myocardial $>$ fibrosis results from intermittent spasm of the small coronary arteries, a form of 'myocardial Raynaud's N phenomenon'. ${ }^{2}$ Additional support for this hypothesis has been provided by other investigators, $O$ who demonstrated cold induced abnormalities on w thallium perfusion in patients with PSS. ${ }^{12}$ Follansbee et al showed that the majority of patientso with PSS and diffuse scleroderma had thallium-201ळ myocardial perfusion defects. ${ }^{13}$

Since abnormalities of small coronary arteries ${ }^{T}$ may have an important role in primary scleroderma 
myocardial disease, vasodilator drugs could be beneficial in PSS patients with myocardial involvement. In the present study we evaluated the effect of the coronary vasodilator dipyridamole on thallium-201 myocardial perfusion in patients with diffuse scleroderma, using single photon emission computed tomography (SPECT).

\section{Patients and methods}

\section{PATIENTS WITH PROGRESSIVE SYSTEMIC} SCLEROSIS

Twenty three patients with PSS with diffuse scleroderma were studied. All patients satisfied the American Rheumatism Association preliminary criteria for definite systemic sclerosis. ${ }^{15}$ In addition to skin thickening of the fingers, hands, and forearms, all patients also had truncal involvement (diffuse scleroderma). None of the patients had the CREST syndrome variant (calcinosis, Raynaud's phenomenon, oesophageal dysmotility, sclerodactyly, telangiectasia) of PSS. ${ }^{16}$ Twenty one of the 23 patients were women. The mean age (SD) was $51.5(8.5)$ years (range 35-66). The duration of disease ranged from one to 30 years (mean (SD) $11 \cdot 8(9 \cdot 3)$ years). Patients were excluded if they had severe pulmonary or renal involvement. Twenty two patients had Raynaud's phenomenon, 10 of whom also had a history of digital ulcers. At the time of the study none of the patients was taking medication for cardiac or vascular disease. All patients gave informed consent for all procedures.

NON-INVASIVE EXAMINATION PROCEDURES All patients with PSS had the following performed: physical examination, pulmonary function testing (routine spirometry with forced vital capacity (FVC), forced volume in one second, and singlebreath diffusing capacity for carbon monoxide $\left.\left(D_{\mathrm{L}} \mathrm{CO}\right)^{17}\right)$, electrocardiograms, standard anteroposterior and lateral chest roentgenograms, and two dimensional echocardiograms.

\section{RESTING AND DIPYRIDAM̄OLE}

TH A L L I U M-201 I M A G I N G

All PSS patients underwent thallium-201 myocardial single photon emission computed tomography, ${ }^{18-20}$ at rest and after coronary artery vasodilatation with intravenous dipyridamole. ${ }^{21-27}$ Resting and dipyridamole studies were performed at one week intervals. The one week delay between the two investigations was preferred to the four hour redistribution images, ${ }^{22}$ mainly because of the lack of information about the elimination rate of dipyridamole by the myocardium of PSS patients.
The order of performing resting and dipyridamole studies was alternated.

Thallium-201 imaging was performed with the subject at rest, using a tomographic gammacamera (CGR Gammatome T 9000). The patient was placed supine with the left arm stretched over the head. Thallium-201 (Mallinckrodt Diagnostica) with an activity of $75 \mathrm{MBq}(2.0 \mathrm{mCi})$ was injected intravenously. Acquisition began within 15 minutes of the tracer administration. Thallium images were recorded for 20 minutes. Thirty two images were recorded on a $180^{\circ}$ rotation basis, each of them digitised in a $64 \times 64$ matrix. Approximately two million counts were accumulated in one study. About 20 transverse slices (6 $\mathrm{mm}$ thick) were reconstructed on a minicomputer (CGR IMAC).

Dipyridamole-thallium imaging was performed with the patient in the supine position. Intravenous dipyridamole (Boehringer-Ingelheim) was infused through a 21 gauge butterfly needle placed in a forearm vein. A calibrated infusion pump delivered the drug at $0.14 \mathrm{mg} / \mathrm{kg}$ of body weight $/ \mathrm{min}$ for four minutes. Blood pressure, heart rate, and electrocardiograms were monitored and all symptoms recorded. One minute after the end of dipyridamole infusion $75 \mathrm{MBq}(2.0 \mathrm{mCi})$ activity of thallium-201 was injected intravenously and the cannula was flushed with $5 \mathrm{ml}$ of saline. The imaging procedure was begun within five minutes of the time of thallium injection. Aminophylline $(250 \mathrm{mg})$, which promptly reverses the effects of dipyridamole, 2225 was available during each procedure.

\section{ANALYSIS OF THALLIUM-201 IMAGES}

The thallium-201 images were interpreted from a computer display. The resting and unprocessed dipyridamole images were displayed side by side for comparison. The use of the same amount of injected radioactivity reduced the normalisation bias observed between different tomographic studies.

Each image was interpreted by three independent experienced observers without knowledge of the patient's clinical history and catheterisation findings. The readers were blinded as to pre- and postdipyridamole scans. Such a qualitative interpretation of thallium images by multiple observers is a highly sensitive and specific test for coronary artery disease. $^{22}$

The analysis was done by visual inspection of the left anterior oblique sets of images, using the three most central slices of the left ventricle (apical, central, and basal). Each of these three slices was divided into three segments (Fig. 1). Thus the left myocardium was divided into nine segments. Tracer activity in each segment was visually graded as $2 \cdot 0$, 


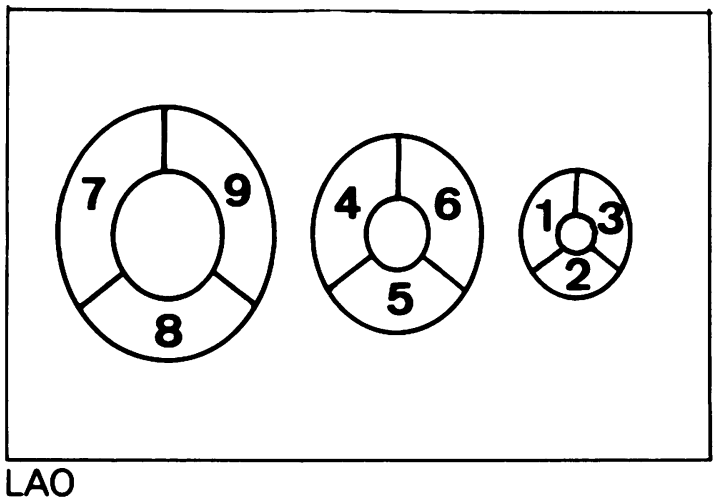

Fig. 1 Schematic representation of the thallium-201 myocardial emission tomography. The three most central slices are shown (left anterior oblique view). Each of the three slices was divided into three segments (1 to 9). $L A O=$ left anterior oblique.

$1 \cdot 5,1 \cdot 0,0 \cdot 5,0$, as previously described. ${ }^{22}$ A value of 2.0 represents the most intense thallium-201 activity and zero represents no activity. The range of normal for each segment was determined from studies of 20 normal control subjects (18 women, two men, mean age (SD) $53.6(8 \cdot 1)$ years, range 35-64 years) evaluated in our laboratory. The three observers' scores for each segment were averaged. Segmental defects on thallium-201 myocardial scans were defined as mean scores of less than $1 \cdot 5$, as previously reported. $^{22}$

If the mean segmental score after dipyridamole increased or decreased by at least 0.5 compared with resting values it was interpreted as an improved, or aggravated, defect.

If the mean segmental score after dipyridamole increased by at least 0.5 and was 1.5 or greater it was interpreted as 'complete improvement'. 22

In each patient a 'global score' was calculated by summing the mean scores of each segment (maximal global score $=18$, minimal global score $=0$ ). If the global score after dipyridamole increased or decreased by at least 2.0 compared with resting values it was interpreted as 'improved', or 'aggravated'

RESTING RADIONUCLIDE

VENTRI C U L O G R A P H Y

Each patient underwent supine resting radionuclide ventriculography with a gammacamera (CGR Acticamera), using in vitro labelling of red blood cells with $555 \mathrm{MBq}(15 \mathrm{mCi})$ of ${ }^{99 \mathrm{~m}} \mathrm{Tc}$. Resting gated blood pool images were acquired for 300000 counts in each of the 16 frames. The best left anterior oblique view with a $10^{\circ}$ caudal tilt was used to separate the ventricles from the atrial images. Left ventricular ejection fraction was determined by a 'two region of interest' method with an automatic $\Rightarrow$. thresholding technique for background subtraction. $\frac{\text { s }}{9}$ Normal resting left ventricular function was defined을 as an ejection fraction of $\geqslant 55 \%$.

Regional wall motion was qualitatively graded as $\frac{\overline{\bar{p}}}{\stackrel{5}{2}}$ normal or hypokinetic. The regional wall motion abnormalities were classified in three segments $s_{\infty}$ matched as closely as possible to the segmental distribution used to grade the thallium-201 images. Differences of opinion between the three indepen- $\vec{\omega}$ dent observers were resolved by consensus.

CATHETERIS ATION PROCEDURE

Nine patients underwent cardiac catheterisation with left ventricular angiography and coronary arteriography according to standard techniques. The $\vec{\infty}$ coronary angiograms were interpreted independentlyo by two experienced observers without knowledge of $\rightarrow$ the scan findings. No patient had an interval changes in cardiac symptoms or electrocardiograms duringo the study period.

STATISTICAL METHODS

Statistical analyses were made with Student's paired and unpaired $t$ test, the sign test, and the correlation $\infty$ test. Calculations were carried out according to the biomedical data program. ${ }^{28}$ Significance considered present if $p \leqslant 0 \cdot 05$.

\section{Results}

CLINICAL FINDINGS

None of the PSS patients had either a previous $\overrightarrow{\vec{O}}$ history of systemic hypertension or a blood pressure above $140 / 90 \mathrm{mmHg}$ during the evaluation. None of the patients had evidence of congestive heart? failure. Nine patients had chest pain consistent with angina pectoris. Five patients had abnormal findings. on electrocardiograms, including one with as pseudoinfarction pattern, three with ST segment' depression, and one with left bundle branch block. None of the patients had cardiac enlargement on standard chest roentgenograms. Echocardiograms $\bigcirc$ showed minimal posterior pericardial disease in fou $\frac{7}{0}$ patients.

Chest radiographs showed normal findings in $15 \mathrm{O}_{\circ}$ patients and mildly abnormal interstitial markings in eight. Pulmonary function findings were normal in 11 patients. Twelve patients had mild restrictivew lung disease (FVC $66-80 \%$ of predicted normal) or an isolated decrease in $\mathrm{D}_{\mathrm{L}} \mathrm{co}(66-80 \%$ of predictedo normal). ${ }^{17}$ None of the patients had either physicalo findings of severe pulmonary hypertension or ${ }^{+}$ electrocardiographic evidence of right ventricular ${ }^{-}$ hypertrophy. 
Table 1 Clinical details and scintigraphic results

\begin{tabular}{|c|c|c|c|c|c|c|c|c|c|c|c|c|}
\hline \multirow{3}{*}{$\begin{array}{l}\text { Patient } \\
\text { No }\end{array}$} & \multirow[t]{3}{*}{ Age } & \multirow[t]{3}{*}{ Sex } & \multirow[t]{3}{*}{$D D$} & \multicolumn{2}{|l|}{$L V F$} & \multicolumn{5}{|c|}{ Number of ${ }^{20 I} \mathrm{Tl}$ defects } & \multicolumn{2}{|l|}{$G S$} \\
\hline & & & & \multirow[t]{2}{*}{$R E F$} & \multirow[t]{2}{*}{$W H$} & \multirow[t]{2}{*}{$R$} & \multirow[t]{2}{*}{$D P D$} & \multicolumn{3}{|c|}{ After $D P D$} & \multirow[t]{2}{*}{$R$} & \multirow[t]{2}{*}{$D P D$} \\
\hline & & & & & & & & $\operatorname{Imp}$ & Unc & Agg & & \\
\hline 1 & 64 & $\mathbf{F}$ & 9 & 57 & + & 8 & 4 & 4 & 3 & 1 & $8 \cdot 00$ & $11 \cdot 50$ \\
\hline 2 & 51 & $\mathbf{F}$ & 24 & 49 & + & 5 & 3 & 4 & 1 & 0 & $10 \cdot 17$ & $12 \cdot 17$ \\
\hline 3 & 66 & $\mathbf{F}$ & 15 & 66 & - & 7 & 4 & 3 & 4 & 0 & $9 \cdot 50$ & $11 \cdot 50$ \\
\hline 4 & 56 & $\mathbf{F}$ & 11 & 60 & - & 4 & 2 & 2 & 2 & 0 & 11.83 & $14 \cdot 50$ \\
\hline 5 & 53 & $\mathbf{F}$ & 1 & 65 & - & 6 & 3 & 3 & 3 & 0 & $10 \cdot 50$ & $12 \cdot 50$ \\
\hline 6 & 49 & $\mathbf{F}$ & 28 & 59 & - & 5 & 0 & 5 & 0 & 0 & $9 \cdot 50$ & $14 \cdot 50$ \\
\hline 7 & 61 & $\mathbf{F}$ & 15 & 55 & - & 7 & 4 & 4 & 3 & 0 & $9 \cdot 00$ & 12.00 \\
\hline 8 & 35 & $\mathbf{F}$ & 9 & 65 & - & 5 & 2 & 3 & 2 & 0 & $10 \cdot 50$ & $12 \cdot 50$ \\
\hline 9 & 37 & $\mathbf{F}$ & 1 & 73 & - & 5 & 1 & 4 & 1 & 0 & $11 \cdot 33$ & $13 \cdot 50$ \\
\hline 10 & 53 & $\mathbf{F}$ & 5 & 67 & + & 9 & 7 & 7 & 2 & 0 & 6.00 & 11.00 \\
\hline 11 & 45 & $\mathbf{F}$ & 11 & 72 & + & 6 & 2 & 5 & 1 & 0 & $10 \cdot 00$ & $12 \cdot 67$ \\
\hline 12 & 53 & $\mathbf{F}$ & 1 & 70 & + & 9 & 5 & 6 & 3 & 0 & $6 \cdot 50$ & $10 \cdot 16$ \\
\hline 13 & 53 & $\mathbf{F}$ & 24 & 77 & - & 5 & 5 & 0 & 5 & 0 & $11 \cdot 00$ & $10 \cdot 83$ \\
\hline 14 & 41 & $\mathbf{F}$ & 14 & 61 & + & 3 & 3 & 0 & 3 & 0 & $11 \cdot 00$ & $11 \cdot 17$ \\
\hline 15 & 46 & $\mathbf{M}$ & 1 & 61 & + & 9 & 9 & 1 & 7 & 1 & 8.83 & 8.83 \\
\hline 16 & 62 & $\mathbf{F}$ & 15 & 67 & - & 2 & 2 & 0 & 2 & 0 & $14 \cdot 00$ & $14 \cdot 34$ \\
\hline 17 & 61 & $\mathbf{F}$ & 30 & 63 & - & 4 & 4 & 0 & 4 & 0 & $11 \cdot 50$ & $12 \cdot 00$ \\
\hline 18 & 50 & $\mathbf{F}$ & 10 & 49 & + & 7 & 6 & 1 & 5 & 1 & $9 \cdot 67$ & 9.67 \\
\hline 19 & 59 & $\mathbf{F}$ & 1 & 69 & - & 8 & 7 & 1 & 6 & 1 & $9 \cdot 83$ & 9.83 \\
\hline 20 & 41 & $\mathbf{M}$ & 3 & 58 & - & 2 & 1 & 1 & 0 & 1 & $13 \cdot 17$ & $13 \cdot 00$ \\
\hline 21 & 43 & $\mathbf{F}$ & 18 & 61 & - & 6 & 5 & 1 & 2 & 3 & $11 \cdot 50$ & $9 \cdot 50$ \\
\hline 22 & 53 & $\mathbf{F}$ & 23 & 49 & + & 8 & 8 & 0 & 2 & 6 & $10 \cdot 33$ & 7.00 \\
\hline 23 & 53 & $\mathbf{F}$ & 3 & 55 & + & 8 & 8 & 0 & 3 & 5 & $10 \cdot 00$ & $7 \cdot 00$ \\
\hline
\end{tabular}

$\mathrm{DD}=$ disease duration; $\mathrm{LVF}=$ left ventricular function; $\mathrm{REF}=$ resting left ventricular ejection fraction: WH=wall hypokinesis; $\mathrm{R}=\mathrm{at}$ rest; $\mathrm{DPD}=$ after dipyridamole; After DPD Imp=improved segments after dipyridamole; After DPD Unc=unchanged segments after dipyridamole; After DPD Agg=aggravated segments after dipyridamole; GS=global score.

All 23 patients had normal serum creatinine concentration (mean (SD) $74(14) \mu \mathrm{mol} / \mathrm{l})$.

\section{RESTING RADIONUCLIDE}

\section{VENTRICU L O GRAPHY}

Resting left ventricular ejection fraction, assessed by radionuclide ventriculography, was normal in all but three PSS patients (mean (SD) $62(8) \%$, range 49-77\%) (Table 1).

Ten patients had hypokinetic regional left ventricular wall motion at rest. All regional wall motion abnormalities were associated with resting thallium defects in the same territories.

\section{RESTING AND DIPYRIDAMOLE}

THA L LI U M-201 IM A G I N G

The results are shown in Table 1.

All 23 PSS patients had abnormalities on resting thallium scans. Since the left myocardium was divided into nine segments in each of the 23 patients a total of 207 segments was studied. Resting thallium defects were found in 138 segments $(67 \%)$. The mean (SD) number of resting thallium defects in each patient was $6.0(2 \cdot 1)$ (range $2-9$; with a median defect number of 6.0 for all 23 patients).
After dipyridamole infusion 55 thallium defects $(40 \%)$ were improved (increase in mean score of $\geqslant 0 \cdot 5), \quad 64$ defects $(46 \%)$ remained unchanged (variation in mean score of $<0 \cdot 5$ ), and 19 defects

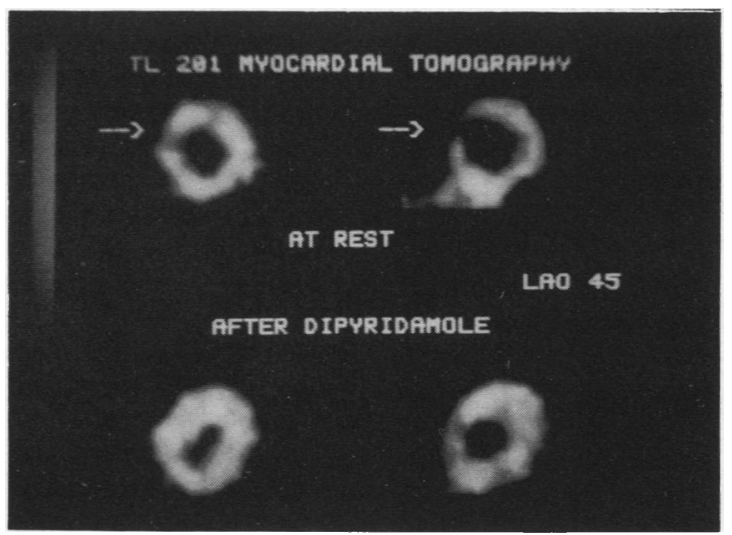

Fig. 2 Resting and dipyridamole-thallium scans showing improvement in a representative patient. There are two defects on the resting images (upper left and upper right: arrows) that fill in on the dipyridamole images (lower left and lower right). LAO $45=45^{\circ}$ left anterior oblique. 
$(14 \%)$ worsened (decrease in mean score of $\geqslant 0 \cdot 5)$. Improvement induced by dipyridamole in a representative patient is shown in Fig. 2.

In each patient an 'improvement index' was calculated as the ratio:

$$
\begin{gathered}
\text { number of improved segments-number of worsened } \\
\text { segments }
\end{gathered}
$$

number of segments with resting thallium defects

The mean (SD) 'improvement index' $(0 \cdot 27(0 \cdot 47))$ was significantly different from $0(\mathrm{p}<0 \cdot 02$, by the $t$ test).

After dipyridamole infusion 43 of the 55 improved segments had a score of $\geqslant 1.5$ and were considered to be normal. Thus the mean (SD) number of segments with thallium defects significantly decreased from $6.0(2 \cdot 1)$ at rest to $4 \cdot 1(2.5)$ after dipyridamole $(\mathrm{p}<0.0001$ by the paired $t$ test).

In the 138 segments with resting thallium defects the mean (SD) score significantly increased from $0.92(0.24)$ at rest to $1.13(0.38)$ after dipyridamole $(\mathrm{p}<0 \cdot 0001$, by the paired $t$ test).

The mean (SD) global score significantly increased from $10.2(1.8)$ at rest to $11.4(2.1)$ after dipyridamole $(\mathrm{p}<0.02$, by the paired $t$ test $)$.

After dipyridamole the global score improved by at least 2.0 in 12 patients and worsened by at least 2.0 in three patients only ( $p=0.05$, by the sign test).

Thus dipyridamole significantly improved all parameters of myocardial perfusion in patients with PSS and diffuse scleroderma.

The thallium results did not correlate with the age of the patients, or with the disease duration, or the resting left ventricular ejection fraction. The differences in thallium results were not statistically significant between patients with chest pain, or interstitial markings, or abnormal pulmonary function findings, and the remainder. Patients with electrocardiogram (ECG) abnormalities, however, had significantly greater numbers of resting thallium defects than did the remainder (mean (SD) $8.0(0 \cdot 7)$ $v 5.4(2.1), \mathrm{p}<0.0003)$. Patients with hypokinetic regional wall motion had significantly greater numbers of resting thallium defects and lower resting global scores than did the remainder (mean (SD) $7.2(2.0)$ v $5.1(1.8), \mathrm{p}<0.02$; and $9.1(1.7) v$ $1.0(1.5), p<0.01$ respectively). Finally, the improvement in global score inversely correlated with the resting global score $(r=0.48 ; p<0.02)$; the best improvement was noted in patients with the lowest resting global scores.

A DVERSE EFFECTS OF DIPYRIDAMOLE Dipyridamole was well tolerated by most of the patients in the study. In most patients systolic blood pressure decreased by $5-10 \mathrm{mmHg}$ (mean (SD) $5(5)$ $\mathrm{mmHg}$ ) and heart rate increased by $5-15$ beats minute (mean (SD) 11 (8)) during the infusion $\Rightarrow$ Three patients complained of mild symptoms, such $\stackrel{5}{?}$ as transient dizziness, headache, or nausea. None ofe the patients developed chest pain or any modification of electrocardiograms after dipyridamole infusion. The adverse effects did not require any treatment of alteration in the protocol. None of the patients wase given intravenous aminophylline.

CATHETERISATION RESULTS

Eight of the nine patients who underwent cardiaco catheterisation had normal left ventricular function. In one patient the left ventricular end diastolicis volume and left ventricular mass were increased to $109 \mathrm{ml} / \mathrm{m}^{2}$ and $107 \mathrm{~g} / \mathrm{m}^{2}$ respectively, and ejection $\sim$ fraction decreased to $46 \%$. The coronary arteriogram results were normal in all but one patient, who had? $80 \%$ stenosis of a small lateral artery. This stenosis $\vec{s}$ did not correlate with a thallium perfusion defect (ato rest or after dipyridamole) or with a wall motion abnormality. Two of the three patients with dipyridamole induced aggravation in thallium defectso underwent cardiac catheterisation and had nornaralcoronary angiography.

\section{Discussion}

The major observation in this study was thato dipyridamole significantly improved thallium-201\% myocardial perfusion in patients with progressive $\mathbb{Q}$ systemic sclerosis with diffuse scleroderma. After $\vec{\sigma}$ dipyridamole infusion the mean number of segments with thallium defects significantly decreased, the? mean score of segments with resting thallium defects and the mean global score significantly increased.

These findings are consistent with clinical and $\bar{Q}$ histopathological results, suggesting an abnormality of the small coronary arteries in primary scleroderma myocardial disease. Symptoms of PSMD includeo chest pain, dyspnoea, palpitations, congestive heart failure, syncope, and sudden death. ${ }^{1-3}$ Angina? pectoris and myocardial infarctions have been seen in PSS patients with normal coronary arteries. ${ }^{2} 3$ One histopathological examination the characteristic manifestation of myocardial involvement in PSS is myocardial fibrosis unrelated to overt disease or narrowing in the large coronary arteries. ${ }^{1-3} \sqrt{\mathrm{E}}$ Concentric intimal hypertophy, narrowing, fibrosis? and fibrinoid necrosis of intramural coronarye arteries and arterioles have been noted in somed studies $^{711} 14$ but not in others. ${ }^{2}$ Bulkley reported ${ }^{9}$ pathological findings consistent with progression from contraction band necrosis through replacement? 
fibrosis in hearts of PSS patients. ${ }^{2}$ The recent studies by Follansbee et $\mathrm{al}^{13}$ and Kahan et $\mathrm{al}^{14}$ also suggested that in association with myocardial fibrosis a functional or structural abnormality of the coronary circulation might be present at the level of the intramyocardial vasculature. In the latter study ${ }^{14}$ the normal mean coronary sinus blood flow at rest in PSS patients with numerous resting thallium defects might be explained by a heterogeneous myocardial perfusion. In this context it is relevant that patients with significant atherosclerotic coronary stenoses may have a normal coronary sinus blood flow at rest, despite frequent thallium-201 perfusion defects. ${ }^{25}$ In PSS patients the dipyridamole induced increase in coronary sinus blood flow ${ }^{14}$ could be due to vasodilatation in normal zones, or in territories with vasospasm of the small coronary arteries, or to collateral vessels that function only after coronary artery vasodilatation. The limitation in coronary reserve $^{14}$ could be due to fibrotic zones or to anatomical lesions of the small coronary arteries.

Follansbee et al demonstrated a high prevalence of abnormalities of myocardial perfusion that can be detected by means of radionuclide techniques in patients with PSS. ${ }^{13}$ These investigators used exercise and redistribution thallium-201 planar scintigraphy. ${ }^{13}$ The present study is the first to use thallium-201 myocardial single photon emission computed tomography to assess the effect of dipyridamole on myocardial perfusion in systemic sclerosis. Emission tomography provides a better sensitivity and also a better interobserver agreement than planar scintigraphy in the detection of transmural myocardial necrosis with thallium-201. ${ }^{19}{ }^{20}$ Furthermore, since histological lesions are small and patchy in primary scleroderma myocardial disease, emission tomography appears to be a more sensitive method than planar scintigraphy (which does not resolve depth) in these patients. Indeed, we found a very high prevalence of resting thallium defects in PSS patients.

Patients with abnormalities on ECG had significantly greater numbers of resting thallium defects than did the remainder. These findings are consistent with those of a recent study which showed that thallium defect scores were greater in PSS patients with septal infarction pattern or ventricular conduction abnormalities than in the remainder. ${ }^{29}$

Patients with hypokinetic regional wall motion had significantly greater numbers of resting thallium defects and lower resting global scores than did the remainder. These results are consistent with the hypothesis that myocardial dysfunction in these patients may be related to both fibrotic and vascular abnormalities.
The coronary flow response to dipyridamole is at least as great as that associated with exercise, but without the physiological increase in myocardial oxygen demand. ${ }^{21}{ }^{30-32}$ Most studies indicate that treadmill exercise is usually associated with a threefold increase in coronary blood flow. ${ }^{30}$ Dipyridamole increases coronary blood flow three to fivefold.$^{31} 33$ The increase in coronary blood flow that occurs with exertion quickly disappears after cessation of exercise; the coronary dilatation secondary to dipyridamole infusion declines at a rate of $50 \%$ per 45 minutes in normal subjects. ${ }^{33}$ The side effects of intravenous dipyridamole are probably not greater than those associated with treadmill exercise tolerance tests in patients with coronary artery disease. ${ }^{21} 32$ Indeed, in the present investigation no PSS patient developed serious side effects: thus dipyridamole appears to be safe in patients with primary scleroderma myocardial disease. Finally, dipyridamole can increase coronary blood flow in patients who cannot achieve intense levels of exercise, such as PSS patients.

Several investigators have shown that in conjunction with a dipyridamole infusion, thallium201 scans reliably detect coronary artery disease. ${ }^{21} 22$ 24-26 In these patients with structural lesions of the large coronary arteries and reversible ischaemia, hypoperfused segments after dipyridamole have a normal or improved perfusion at rest; non-perfused necrotic segments show no change between dipyridamole and rest. In a few cases a 'reverse' redistribution phenomenon has been described: segments that appear normal after dipyridamole are hypoperfused at rest; this may be explained by the existence of collateral vessels that function only under conditions of stress. ${ }^{27}$

The present findings are in marked contrast with those usually obtained in patients with coronary artery disease. We showed that dipyridamole significantly improved thallium-201 myocardial perfusion abnormalities in PSS patients. It should be noted that patients with the best dipyridamole induced improvement had the lowest resting global scores. These findings may be explained by a high prevalence of reversible (vascular) abnormalities, suggesting that vasodilator drugs may be beneficial even in PSS patients with severe thallium-201 perfusion abnormalities at rest. The mechanism of action of dipyridamole on thallium-201 myocardial perfusion defects in our patients cannot be determined from this study. These results, however, are compatible with the hypothesis that the previously discussed abnormalities may coexist in variable proportions in different myocardial segments and patients. A resting thallium defect due to vasospasm of the small 
coronary arteries may be improved after coronary artery dilatation with dipyridamole. The hypothesis that the dipyridamole induced increased perfusion of normal areas surrounding some defects might make defects appear to diminish, while in fact the perfusion of the fibrotic areas may not be changed, cannot be excluded; however, this possibility is considerably reduced by the tomographic technique, as compared with planar scintigraphy. Conversely, resting thallium defects due to fibrosis or to anatomical lesions of the intramyocardial vasculature may be unchanged or even aggravated after dipyridamole, as previously described in patients with severe atherosclerotic stenoses of the large coronary arteries. ${ }^{34} 35$

The results of the present study demonstrate that dipyridamole significantly improves thallium-201 myocardial perfusion in patients with progressive systemic sclerosis with diffuse scleroderma. A long term controlled study of small coronary artery vasodilator drugs in the treatment of PSS patients with myocardial perfusion abnormalities is warranted.

We thank Mrs Magali Vallet-Amor for expert secretarial assistance.

\section{References}

1 Botstein G R, LeRoy E C. Primary heart disease in systemic sclerosis (scleroderma): advances in clinical and pathologic features, pathogenesis, and new therapeutic approaches. Am Heart $J$ 1981; 102: 913-9.

2 Bulkley B H. Progressive systemic sclerosis: cardiac involvement. Clin Rheum Dis 1979; 5: 131-49.

3 Bulkley B H, Klacsmann P G, Hutchins G M. Angina pectoris, myocardial infarction and sudden cardiac death with normal coronary arteries: a clinicopathologic study of 9 patients with progressive systemic sclerosis. Am Heart $J$ 1978; 95: 563-9.

4 Medsger T A Jr, Masi A T, Rodnan G P, Benedek T G, Robinson H. Survival with systemic sclerosis (scleroderma): a life-table analysis of clinical and demographic factors in 309 patients. Ann Intern Med 1971: 75: 369-76.

5 LeRoy E C. Connective tissue synthesis by scleroderma skin fibroblasts in cell culture. J Exp Med 1972; 135: 1351-62.

6 Buckingham R B, Prince R K, Rodnan G P, Taylor F. Increased collagen accumulation in dermal fibroblast cultures from patients with progressive systemic sclerosis (scleroderma). J Lab Clin Med 1978; 92: 5-21.

7 D'Angelo W A, Fries J F, Masi A T, Shulman L E. Pathologic observations in systemic sclerosis (scleroderma): a study of fifty-eight autopsy cases and fifty-eight matched controls. Am J Med 1969; 46: 428-40.

8 Campbell P M, LeRoy E C. Pathogenesis of systemic sclerosis: a vascular hypothesis. Semin Arthritis Rheum 1975; 4: 351-68.

9 Norton W L, Nardo J M. Vascular disease in progressive systemic sclerosis (scleroderma). Ann Intern Med 1970; 73: 317-24.

10 Gupta M P, Zoneraich S, Zeitlin W, Zoneraich O, D'Angelo W. Scleroderma heart disease with slow flow velocity in coronary arteries. Chest 1975; 67: 116-9.

11 James T N. De subitaneis mortibus. VIII Coronary arteries and conduction system in scleroderma heart disease. Circulation 1974; 50: 844-56.
12 Alexander E L, Firestein G S, Leitl G, et al. Scleroderma heart disease: evidence for cold-induced abnormalities of myocardial function and perfusion [Abstr]. Arthritis Rheum 1981; 24 . (suppl): S58.

13 Follansbee W P, Curtiss E I, Medsger T A Jr, et al. Physiologic $\stackrel{\overrightarrow{\mathcal{S}}}{+}$ abnormalities of cardiac function in progressive systemic $\bar{C}$ sclerosis with diffuse scleroderma. $N$ Engl J Med 1984; 310: 142-8.

14 Kahan A, Nitenberg A, Foult J M, et al. Decreased coronary reserve in primary scleroderma myocardial disease. Arthritis Rheum 1985; 28: 637-46.

15 Subcommittee for Scleroderma Criteria of the American $\mathscr{C}$ Rheumatism Association Diagnostic and Therapeutic Criteria $\overrightarrow{0}$ Committee. Preliminary criteria for the classification of systemic sclerosis (scleroderma). Arthritis Rheum 1980; 23: $\vec{\omega}$ 581-90.

16 Rodnan G P, Jablonska S, Medsger T A Jr. Classification and nomenclature of progressive systemic sclerosis (scleroderma). Clin Rheum Dis 1979; 5: 5-13.

17 Weinberger S E, Johnson T S, Weiss S T. Use and or interpretation of the single-breath diffusing capacity. Chest 1980; 78: 483-8.

18 Holman B L, Hill T C, Wynne J, Lovett R D, Zimmerman R E, Smith E M. Single-photon transaxial emission computed tomography of the heart in normal subjects and in patients with infarction. J Nucl Med 1979; 20: 736-40.

19 Maublant J, Cassagnes J, LeJeune J J, et al. A comparisono between conventional scintigraphy and emission tomographyd with thallium-201 in the detection of myocardial infarction. $J \frac{3}{0}$ Nucl Med 1982; 23: 204-8.

20 Tamaki N, Mukai T, Ishii Y, et al. Clinical evaluation of thallium-201 emission myocardial tomography using a rotatigg gamma camera: comparison with seven-pinhole tomograph $J$ G Nucl Med 1981; 22: 849-55.

21 Francisco D A, Collins S M, Go R T, Ehrhardt J C, Van K習O O C, Marcus M L. Tomographic thallium-201 myocardial perfusion scintigrams after maximal coronary artery vasodilation wtih intravenous dipyridamole. Comparison of qualitative and quantitative approaches. Circulation 1982; 66:용 370-9.

22 Leppo J, Boucher C A, Okada R D, Newell J B, Strauss H W $\overrightarrow{\vec{A}}$ Pohost G M. Serial thallium-201 myocardial imaging after dipyridamole infusion: diagnostic utility in detecting coronary stenoses and relationship to regional wall motion. Circulation 1982; 66: 649-57.

23 Gould K L. Noninvasive assessment of coronary stenoses by myocardial perfusion imaging during pharmacologic coronarye vasodilatation. I. Physiologic basis and experimental validation Am J Cardiol 1978; 41: 267-78.

24 Gould K L, Westcott R J, Albro P C, Hamilton G W Noninvasive assessment of coronary stenoses by myocardia? imaging during pharmacologic coronary vasodilatation. II Clinical methodology and feasibility. Am J Cardiol 1978; 41 을 279-87.

25 Albro P C, Gould K L, Westcott R J, Hamilton G W, Ritchie J L, Williams D L. Noninvasive assessment of coronary stenoses by myocardial imaging during pharmacologic coronaryn vasodilatation. III. Clinical trial. Am J Cardiol 1978; 42:S 751-60.

26 Josephson M A, Brown B G, Hecht H S, Hopkins J, PierceN C D, Petersen R B. Noninvasive detection and localization of coronary stenoses in patients: comparison of resting dipyridamole and exercise thallium-201 myocardial perfusion imaging. Am Heart J 1982; 103: 1008-18.

27 Demangeat J L, Constantinesco A, Mossard J M, Chambron J, $₫$ Voegtlin R. Evaluation of myocardial perfusion and leff ventricular function by ${ }^{201} \mathrm{~T} 1$ scintigraphy after dipyridamole $T$ Eur J Nucl Med 1981; 6: 491-503. 
28 Dixon W J. BMDP statistical software. Berkeley, Calif.: University of California Press, 1981.

29 Follansbee W P. Curtiss E I, Rahko P S, et al. The electrocardiogram in systemic sclerosis (scleroderma). Study of 102 consecutive cases with functional correlations and review of the literature. Am J Med 1985; 79: 183-92.

30 Heiss $\mathrm{H} \mathrm{W}$. Coronary blood flow at rest and during exercise. In: Rackamn $\mathrm{H}$, Hahn $\mathrm{C} \mathrm{H}$, eds. Ventricular function at rest and during exercise. Berlin: Springer, 1976: 17-9.

31 Strauer B E. Ventricular function and coronary hemodynamics in hypertensive heart disease. Am J Cardiol 1979: 44: 999-1006.

32 Ellestad M H, Cooke B M, Greenberg P S. Stress testing: clinical application and predictive capacity. Prog Cardiovasc Dis 1979; 21: 431-60.

33 Brown B G, Josephson M A, Petersen R B, et al. Intravenous dipyridamole combined with isometric handgrip for near maximal acute increase in coronary flow in patients with coronary artery disease. Am J Cardiol 1981; 48: 1077-85.

34 Becker L C. Conditions or vasodilator-induced coronary steal in experimental myocardial ischemia. Circulation 1978; 57: 1103-10.

35 Feldman R L, Nichols W W, Pepine C J, Conti C R. Acute effects of intravenous dipyridamole on regional coronary hemodynamics and metabolism. Circulation 1981; 62: 333-44. 